\title{
Intussusception in Children - Pearls in Nonsurgical Management
}

\author{
Rengarajan $\mathrm{R}^{1}$, Venkatesa Mohan $\mathrm{N}^{2}$, Alex $\mathrm{Jc}^{3}$, Raghul $\mathrm{M}^{4}$ \\ ${ }_{1,2,3,4}$ (Department of Paediatric Surgery, Coimbatore Medical College Hospital, India)
}

\begin{abstract}
Intussusception is one of the most common abdominal emergencies affecting children less than 2 years with tailored treatment bystanding the mortality rate to less than 1\%. Our study included children with intussusception with all of them undergoing colour doppler of the involved bowel and definitive management was initiated by ultrasound guided hydrostatic reduction or surgery. The predictive indicators for hydrostatic reduction and the usefulness of Doppler for successful reduction was evaluated. Of the 75 children , 42 presented within 24 hours of onset of symptoms (56\%), 26 within 48 hours ( 34\%) and 7 after 72 hours (10\%). Ultrasound revealed pathological lead point in 8 cases pre-operatively (73\%) and free fluid in 9 (90\%), with 16 (94.11\%) of them ending up in surgery. Doppler sensitivity in identifying the viability of the involved bowel was $98.7 \%$. Radiological guided reduction had 90\% success in children who presented within 24 hours . Earlier presentation and good Doppler flow had a better chance of hydrostatic reduction with delayed presentations, pathological lead points and presence of free fluid invariably ending in surgery. Doppler plays a major role to prempt treatment modality and hence to be included as a part of routine workup.
\end{abstract}

Keywords: bowel gangrene, doppler, intussusception, ultrasound guided reduction

\section{Introduction}

Intussusception is one of the most common causes of acute abdomen in infants and toddlers. It often causes intestinal obstruction among these children. It is described as invagination of proximal portion of the intestine into distal portion of the intestine.Though $75 \%$ of them occur within first 2 years of life ${ }^{[1]}$, it more commonly affects between 3 to 9 months of age ${ }^{[1]}$. Intussusception must be treated as an emergency with involvement of surgeon right from the presentation, confirming the diagnosis and deciding the modalities of treatment as either surgical or non-surgical methods such as ultrasound guided hydrostatic reduction. In this era of minimally invasive surgery, every child should be given the benefit of non-invasive techniques. Ultrasound guided hydrostatic reduction is becoming increasingly popular in the treatment of intussusception. The major adoption in the treatment of intussusception is increasing use of hydrostatic reduction. The same modality of treatment was initially advocated by Hirschsprungs in $1876^{[2]}$. In an effort to identify the group of children who would benefit from ultrasound guided hydrostatic reduction, we are trying to identify the predictive indicators for successful hydrostatic reduction with least morbidity by employing ultrasonogram and Doppler in assessing the viability of bowel and a successful reduction.

\section{Aims Of The Study}

2.1To evaluate the duration of illness prior to presentation as a predictor for successful reduction.

2.2Usefulness of Doppler as a predictor for successful reduction.

2.3To evaluate the predictive indicators for hydrostatic reduction.

\section{Materials And Methods}

This was a prospective study of 75 patients with intussusception admitted in Paediatric surgical ward, Coimbatore Medical College and Hospital between July 2014 and February 2017. Children who presented with peritonitis were excluded from the study.All children who were diagnosed to have intussusception by ultrasonogram underwent colour doppler study of the involved bowel and the findings were recorded and following measures were taken prior to definitive management either by ultrasound guided hydrostatic reduction or surgery.

$>$ Resuscitation

$>$ Adequate hydration

$>$ Nasogastric aspiration

$>$ Preparation of operation theatre

$>$ Informing anaesthetist

$>$ Getting an informed and written consent.

After making sure of all the above mentioned measures and based on the preliminary ultrasound report, all children who had colour doppler flow and who did not have pathological lead point and free fluid in 
ultrasonogram, underwent ultrasound guided hydrostatic reduction. Those children who did not show colour doppler flow underwent surgery. During Doppler study, presence or absence of blood flow in the intussceptum will be recorded.

\section{Criteria For Successful Reduction}

Disappearance of intussusceptions Saline filled small bowel loops Free retrograde passage of saline across caecum and ileocaecal valve and terminal ileum. Visualization of ileocaecal valve Those children who were not eligible for ultrasound guided hydrostatic reduction underwent either laparoscopic reduction or laparotomy and manual reduction and if necessary resection and anastomosis. All the findings were recorded and analysed.A total of 75 patients who were diagnosed to have intussusceptions were included in the study for the evaluation of predictive indicators for hydrostatic reduction under ultrasound guidance, during the period of the study. Of the 75 children included in the study all were less than 8 yrs of age. Among them 48 children were less than 1 year of age, accounting for $64.5 \%$ and a total of 61 patients were below 2 years of age accounting for $81.3 \%$.Of the 75 children, there were 47 male $(62.5 \%)$ children and 28 female $(37.5 \%)$ children, with a ratio of $1.6: 1$

\section{Symptoms And Signs}

\begin{tabular}{|c|c|c|c|c|}
\hline Symptoms & $\begin{array}{c}\text { Abdominal } \\
\text { pain }\end{array}$ & Vomiting & Blood in stools & Mass palpable \\
\hline Total & 75 & 54 & 15 & 6 \\
\hline
\end{tabular}

Distribution According To Duration At Presentation

\begin{tabular}{|c|c|c|}
\hline$<24$ hours & $<48$ hours & $>72$ hours \\
\hline 42 & 26 & 7 \\
\hline
\end{tabular}

\subsection{Success And Failure Rates Of Ultrasonogram}

In all the USG could identify the type of intussusception.Among 11 cases which had Pathological lead point (PLP) during surgery, USG was able to identify 8 cases preoperatively.Among 9 cases which had free fluid and gangrene intra-operatively USG was able to identify 6 cases.

Type Of Intussusceptions In Ultrasonogram

\begin{tabular}{|l|c|}
\hline & Number of cases \\
\hline Ileo - colic & 72 \\
\hline Ileo - ileal & 2 \\
\hline Ileo -ileo-colic & 1 \\
\hline
\end{tabular}

Pathological Lead Point In Ultrasonogram

\begin{tabular}{|c|c|c|}
\hline Pathological lead point & Detected by ultrasound & Detected intraoperatively \\
\hline 11 & $\mathbf{8}$ & $\mathbf{3}$ \\
\hline & $\mathbf{7 2 . 7 2 \%}$ & $\mathbf{2 7 . 2 7 \%}$ \\
\hline
\end{tabular}

Doppler Study

\begin{tabular}{|l|c|c|c|c|}
\hline & Flow present & \% & Flow absent & \% \\
\hline Total & 71 & $92 \%$ & 4 & $8 \%$ \\
\hline
\end{tabular}

Doppler Success Rate

\begin{tabular}{|l|c|c|c|c|}
\hline & Total Cases & Healthy Bowel & $\begin{array}{c}\text { Gangrene } \\
\text { Bowel }\end{array}$ & $\%$ \\
\hline $\begin{array}{l}\text { Flow } \\
\text { present }\end{array}$ & 71 & 70 & 1 & $98.7 \%$ \\
\hline Flow absent & 4 & 0 & 4 & $100 \%$ \\
\hline
\end{tabular}

Reduction Success Compared To Duration Of Symptoms

\begin{tabular}{|l|c|c|c|c|c|}
\hline $\begin{array}{c}\text { Duration } \\
\text { of } \\
\text { Symptoms }\end{array}$ & $\begin{array}{c}\text { Number of } \\
\text { Children }\end{array}$ & $\begin{array}{c}\text { Successful } \\
\text { Reduction }\end{array}$ & $\begin{array}{c}\text { Failed } \\
\text { Reduction }\end{array}$ & $\begin{array}{c}\text { Reduction } \\
\text { not done }\end{array}$ & $\begin{array}{c}\text { Success } \\
\text { Percentage }\end{array}$ \\
\hline$<24 \mathrm{hrs}$ & 42 & 38 & 4 & Nil & $90 \%$ \\
\hline$<48 \mathrm{hrs}$ & 26 & 13 & 5 & 8 & $50 \%$ \\
\hline$>72 \mathrm{hrs}$ & 7 & 3 & 2 & 2 & $42 \%$ \\
\hline & 75 & 54 & 11 & 10 & \\
\hline$\%$ & & $80 \%$ & $16.9 \%$ & $13.3 \%$ & \\
\hline
\end{tabular}




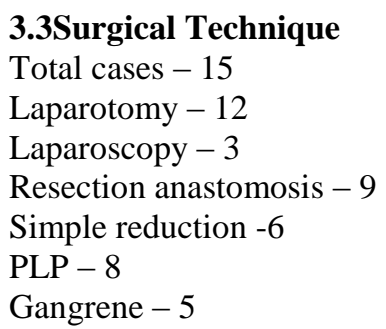

Pathological Lead Points Causing Intussusception

\begin{tabular}{|l|l|}
\hline Meckels Diverticulum & 2 \\
\hline Appendix & 2 \\
\hline Intestinal Polyp & 2 \\
\hline Mesenteric Adenitis & 2 \\
\hline Total & 8 \\
\hline
\end{tabular}

\subsection{Recurrence}

One child had recurrence after 24 hours, two children had recurrence after 1 week and two children had recurrence after 1 month.

\section{Discussion}

Incidence of intussusceptions among these 75 children, the more affected children are within 2 years of age total 61 children accounting up to $81.3 \%$. Literature review also suggests that $75 \%$ of children less than 2 years are affected ${ }^{[3]}$. Among these 61 children 48 children are less or equal to 1 year of age accounting up to $78.6 \%$. Only 8 children are between 1 to 2 years of age (13\%). So, according to our study less than 1 year children are commonly affected than 1 to 2 years of age. More than 5 years only one child had intussusception accounting for only $2 \%$. Among children less than a year, children belonging to 5 to 6 months are more affected accounting for $29 \%$, followed by 7 months to 1 year of age. But if we calculate from 3 months to 9 months they account for $64.5 \%$, which is comparable to the literature review.Incidence among male is more compared to female children accounting for up to $62.5 \%$, with a ratio of $1.6: 1$, which is comparable with literature which gives a ratio of 2:1.

Below one year of age male children are more commonly affected $68 \%$ compared to female $32 \%$. Among the symptoms and signs, the most common symptoms which were present in all children were abdominal pain, followed by vomiting accounting for $72 \%$, and other recorded symptom is blood in stools accounting for $20 \%$. Mass palpable on abdominal examination accounted for $8 \%$ as the children present at an early stage of the disease process. Among all the 75 children, 42 children presented within 24 hours of onset of symptoms (56\%), 26 children presented within 48 hours of onset of symptoms( $34 \%$ ), and 7 children presented after 72 hours of onset of symptoms accounting for $10 \%$. Ultrasound was able to find the type of intussusceptions in all the 75 cases, among those ileo-colic intussusceptions was the commonest accounting for $94 \%$, which is comparable to the literature review. 2 children had ileo-ileal intussusceptions and one child had ileo-ileo-colic intussusceptions. All these three children underwent surgical intervention; ileo-ileo-colic child had meckel's diverticulum underwent resection and anastomosis, ileo-ileal children, one had gangrene bowel underwent resection and anastomosis and one child underwent laparotomy manual reduction.Ultrasound was able to find out pathological lead point in 8 cases pre-operatively among 75 cases, but intra-operatively 3 more cases had pathological lead point which was missed by ultrasonogram. So the success rate of finding a pathological lead point in ultrasonogram is $72.72 \%$. This is owing to bowel wall edema or the gangrenous nature of the pathological bowel making the pin point diagnosis of a lead point in these cases difficult.

Ultrasonogram identified free fluid in 5 children pre-operatively and those 5 children were taken up for surgery, and they had gangrene bowel with free fluid, 1 child free fluid was missed in ultasonogram but intraoperatively free fluid was present. Hence, the success percentage to identify free fluid is $90 \%$.Doppler study of the involved segment was done for all the 75 children, who showed flow across the involved bowel in 71 children accounting to $94.6 \%$, and flow was not present in 4 children accounting to 5\%. This result is comparable to the study done by Lagalla et $\mathrm{al}^{[4]}$. Among the 71 children who showed flow in doppler study, one child went for laparotomy for failed reduction and intraoperatively found to have gangrene bowel, other four children who did not have flow in doppler study had gangrene bowel intra-operatively, hence the sensitivity of Doppler in identifying the viability of the involved bowel is $98.7 \%$ and chance of a false negative report is 1.3\%.Our report is comparable to the study done by M S Kong et al, Lim.H.K et al and Lam.A.H ${ }^{[5,6,7]}$.

In comparing the success rate of radiological guided reduction, we have a success rate of $83.3 \%$, which is comparable to the studies done by Kong et al, Lim et al and Lam et al. Among these 75 children 65 children underwent hydrostatic reduction; all these children had shown blood flow across the involved segment in 
doppler study and did not have free fluid abdomen or pathological lead point prior to reduction. Among these children hydrostatic reduction was successful in 54 cases accounting up to $83 \%$ which is comparable to the literature review which reports $80-90 \%$ success rate, in 11 children hydrostatic reduction failed, among that 3 of them found to have pathological lead point intraoperatively, one child had a intestinal polyp and two children had meckel's diverticulum. One more child who showed flow in Doppler and no free fluid pre-operatively had a gangrene bowel intra-operatively. In the study done by Lam A.H Doppler study failed to identify gangrene bowel in $40 \%$ of cases. Rest of the four children underwent simple reduction. Success of hydrostatic reduction is compared to the duration of onset of symptoms, in that, those children who presented to us within 24 hours of onset accounted for 42 among them 38 had successful reduction with a percentage of 90 . Four of them had failed reduction that underwent laparotomy and simple reduction was done. One of them showed blood flow across the involved bowel in Doppler but reduction failed laparotomy revealed bowel gangrene.

Twenty six presented within 48 hours, among them 13 had successful reduction, 5 had failed reduction and 8 of them did not undergo reduction. Among the four who did not undergo reduction one child had a PLP in ultrasonogram and three others did not show blood flow in Doppler. Two failed reduction child had laparotomy and simple reduction. The success percentage in 48 hours group is 50\%. Seven children presented after 72 hours of onset, among them three had successful reduction and two had failed reduction, in that one child had a PLP (meckel's diverticulum) intra-operatively which ultrasonogram could not identify and other child had simple reduction. Two children did not undergo reduction because one had PLP pre-operatively by USG and one child did not have flow in Doppler. The success percentage in 72 hours group is $42 \%$.From this, those children who present early within 24 hours have successful reduction rate compared to late presentation. This result is comparable to the literature review which quotes a similar result.Our result of successful reduction against duration of presentation is comparable to the study done by E.D.van den Ende et al, Md Shakhawat Hossain et al and Kaiser AD et al. Among the 75 children, 15 of them under went surgical management with a percentage of twenty . Eighteen children underwent laparotomy and three children underwent laparoscopic surgery. In the study by Lam et al ${ }^{[7]}$, they had $50 \%$ of their undergoing surgery, because their patients belonged to delayed presenting group.Six of the children had simple reduction, and nine of them had resection anastomosis. Among the children who underwent resection anastomosis, five of them had gangrene bowel and four of them had pathological lead point two were meckel's diverticulum and other two were polyp, which was later reported as Peutz jeghers polyp. All children who underwent surgery had the same type of intussusceptions intra-operatively which was identified by ultrasonogram. Three children underwent laparoscopic surgery, with appendix as a pathological lead point in one, appendicectomy and reduction was done laparoscopically.

Among the eight children who had pathological lead point, two had meckel's diverticulum, two had appendix, and two had intestinal polyp and mesenteric lymph node in two children. Each group of patients accounted for $25 \%$. In our study, those children who presented after 5 years of age either had pathological lead point or complicated intussusceptions. In our study, 3 children had recurrences. These children had a successful hydrostatic reduction for the first time. One child had recurrence within 24 hours of first reduction; one child had recurrence after 1 week and other had recurrence after one month.The recurrence rate in our study is $6 \%$ which is comparable with the literature ${ }^{[3]}$. All the three recurrences were treated with hydrostatic reduction and were successful. We did not have a case of multiple recurrences. There was no mortality in our series, which is comparable to the reports of studies from developed countries which are less than $1 \%{ }^{[3]}$

\section{Conclusion}

Early presentation within 24 hours has $90 \%$ success rate compared to late presentation thus serving as a good predictor for successful hydrostatic reduction. Delayed presentation invariably leads to bowel ischemia and hence hydrostatic reduction is promptly avoided and without undue time delay proceeded with surgery. Ultrasonogram findings of pathological lead point, free fluid and small bowel involvement are predictors to avoid hydrostatic reduction. Ability of Doppler to predict the viability of involved bowel is $98.7 \%$ and further has a 100\% detection rate for gangrenous bowel and hence a strong predictor to frame emergent treatment protocols ( hydrostatic reduction vs surgery ) thus decreasing morbidity.

\section{Bibliography}

[1]. Ein S.H., Stephens C.A.: Intussusception: 354 cases in 10 years. J Pediatr Surg 1971; 6:16

[2]. Hirschsprung H.: Tilfaelde af subakut tarminvagination. Hospitals-Tilende 1876; 3:321.

[3]. Principles and practice paediatric surgery,6- Authors- $7^{\text {th }}$ edition; 2153

[4]. Lagalla R, Caruso G, Novara V, Derchi LE, Cardinale AE. Color Doppler ultrasonography in pediatric intussusception. J Ultrasound Med. 1994 Mar;13(3):171-4.

[5]. Lim HK, Bae SH, Lee KH, Seo GS, Yoon GS. Assessment of reducibility of ileocolic intussusception in children: usefulness of color Doppler sonography. Radiology. 1994 Jun;191(3):781-5.

[6]. Kong M S et al.: Factors related to detection of blood flow by color doppler ultrasonography in intussusceptions. J Ultrasound Med 16(2):141-4. February 1997. 
[7]. Lam $\mathrm{AH}^{1}$, Firman K.: Value of sonography including color Doppler in the diagnosis and management of long standing intussusception. Pediatr Radiol. 1992;22(2):112-4.

[8]. E D van den Ende, J H Allema, F W J Hazebroek, P J Breslau.: Success with hydrostatic reduction of intussusception in relation to duration of symptoms. Arch Dis Child 2005; 90:1071-1072 doi:10.1136/adc.2004.066332.

[9]. Md Shakhawat Hossain, Md Ashraf Ul Huq, Jafrul Hannan, Kaniz Hasina, RN Sarker.: Role of Ultrasound-Guided Hydrostatic Reduction of Intussusception in Children with Early Presentation. Journal of Paediatric Surgeons of Bangladesh: Vol 3, No 2 (2012).

[10]. Kaiser AD, Applegate KE, Ladd AP.: Current success in the treatment of intussusception in children. Surgery. 2007 Oct; 142(4):469-75; discussion 475-7. 